\title{
Technological Unemployment, Leisure Occupation, and the Human Project
}

\author{
Luciano Floridi
}

Published online: 6 May 2014

(C) Springer Science+Business Media Dordrecht 2014

In 1930, John Maynard Keynes published a masterpiece that should be a compulsory reading for any educated person, a short essay entitled Economic Possibilities for our Grandchildren (Keynes 1930, 1972). ${ }^{1}$ It was an attempt to see what life would be like if peace, prosperity and techno-scientific developments were increasingly part of humanity's future. Of course, things went otherwise. The Great Depression begun in the same year, and World War II soon followed. In the subsequent decades, other disasters, conflicts and crises awaited humanity. The essay became a philosophical exercise that could collect dust in the libraries. Yet the fact that history took such terrible and tragic steps back does not in any way detract from Keynes' brilliant insights. And to a generation that never saw enemy tanks in the streets of Paris or Rome, and will celebrate the hundredth anniversary of the end of World War II, the essay has plenty of lessons to teach, especially about what we want to achieve in the future, our human project.

According to Keynes, roughly around the time of the Renaissance, techno-scientific development, capital growth and the mechanism of compound interest determined a sudden change in history, after which the rate of improvement in standards of living begun to accelerate steadily and progressively. If left undisturbed - Keynes knew very well that this conditional often was a counterfactual — these three factors are sufficient to solve

the economic problem, [that is] the struggle for subsistence, [...] the primary, most pressing problem of the human race - not only of the human race, but of the whole of the biological kingdom from the beginnings of life in its most primitive forms [my emphasis].

Keynes thought that the economic problem was not going to be eliminated for at least another hundred years and that progress towards its solution was incremental, resilient and relentless. So, he argued that the economic problem, despite its magnitude

\footnotetext{
${ }^{1}$ All references are from the 1931 online version of Keynes (1930) provided by Project Gutenberg, so pages are left unspecified. I am sure Keynes would have found such free access to information coherent with the philosophy of the essay.
}

L. Floridi $(\bowtie)$

Oxford Internet Institute, University of Oxford, 1 St Giles, Oxford OX1 3JS, UK

e-mail: luciano.floridi@oii.ox.ac.uk 
and significance, is not humanity's 'permanent problem'. He was right, at least in principle. Nature and human stupidity may of course make a wreckage of any attempt to solve the economic problem, but-barring any major disaster either accidental or self-inflicted - safe and sustainable techno-science, sound economy and decent politics will defy one day Genesis 3:17-19:

Cursed is the ground because of you;

through painful toil you will eat food from it

all the days of your life.

It will produce thorns and thistles for you,

and you will eat the plants of the field.

By the sweat of your brow

you will eat your food.

Neutralising Genesis' curse is a good plan. In fact, it was always the plan. For Genesis 3:17-19 is nothing else than the first step in a de-bugging strategy that explicitly identifies the problem that needs to be fixed in nature. Solving the economic problem has been part of the human project since day one. It was the plan when we invented the wheel and the plough. It was still the plan even when we plundered, pillaged, killed, raped and enslaved each other. For millennia, we just did not have the necessary resources and often squandered whatever few of them we had painfully accumulated. We had to wait for the right breakthroughs in science, technology and capital and for the investment of billions of person-hours. These assets started paying off at the beginning of the modern era, leading to Keynes' reflections in the 1930s. By then, as Keynes wrote, there was

no harm in making mild preparations for our destiny.

Solving the economic problem, however, is coupled to a second problem, which Keynes, with remarkable acumen, called 'technological unemployment'. This too has always been part of the human project:

We are being afflicted with a new disease of which some readers may not yet have heard the name, but of which they will hear a great deal in the years to come - namely, technological unemployment. This means unemployment due to our discovery of means of economising the use of labour outrunning the pace at which we can find new uses for labour. But this is only a temporary phase of maladjustment. All this means in the long run that mankind is solving its economic problem [emphasis in the original text].

Recall that Keynes wrote this in 1930. Turing is only 18 years old and has just failed to win a scholarship to Trinity College Cambridge (fortunately he will win one the following year to King's College, Keynes' college, as it happens). There is not even the idea of a computer, let alone any fear that computers may steal jobs. Robots are science fiction. Yet Keynes was prescient. Figures 1 and 2 illustrate what the 'discovery of means of economising the use of labour' has represented for the nature of employment since 1991. Agriculture is employing fewer and fewer people, and if jobs in industry 


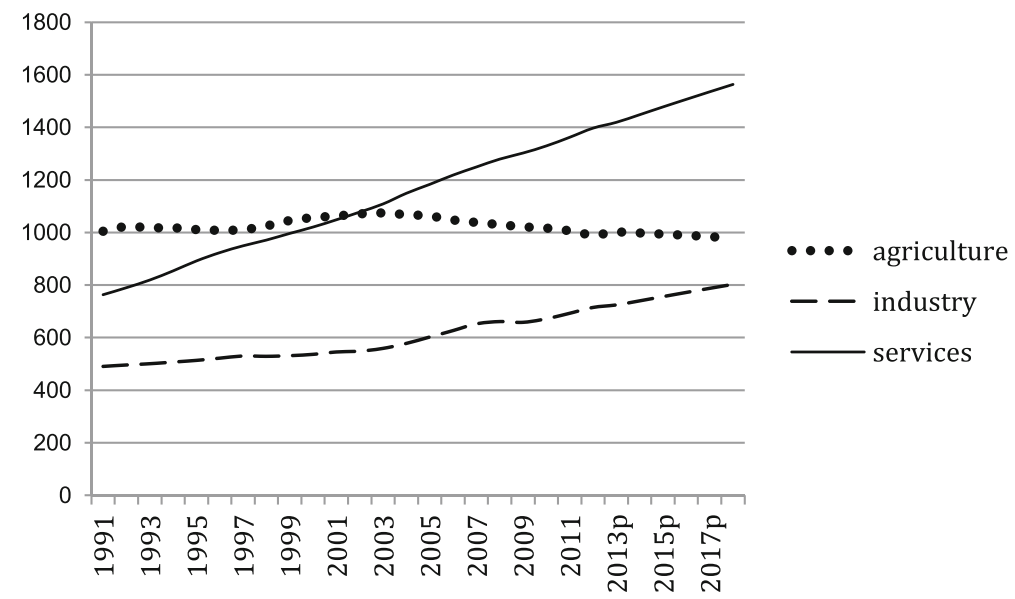

Fig. 1 Total employment by sector globally (millions). $P$ projection. Source: International Labour Organisation-Trends Econometric Models, October 2013

are still growing globally, they are decreasing or stable in developed economies and the EU.

The picture is even starker in the USA (The Economist 18 January 2014), where the shares of employment in agriculture and manufacturing have declined sharply since the 1950 s, to less than $2 \%$ and less than $10 \%$, respectively, with close to $90 \%$ of jobs to be found in services and government (Fig. 3). As Keynes expected, almost everybody is handling software, very few hardware, and almost nobody bioware. The amount of free time has been growing steadily. We live longer and are less poor.

Massive and fast shifts in the workforce from one sector to another in a matter of a few decades make 'technological unemployment' a macroscopic issue, but, following Keynes, we should not mistake this issue for the fundamental problem that needs to be addressed. For it is rather the welcome, if painful, evidence that the economic problem is being solved. It is a cost worth paying, although not without caution. For there is a

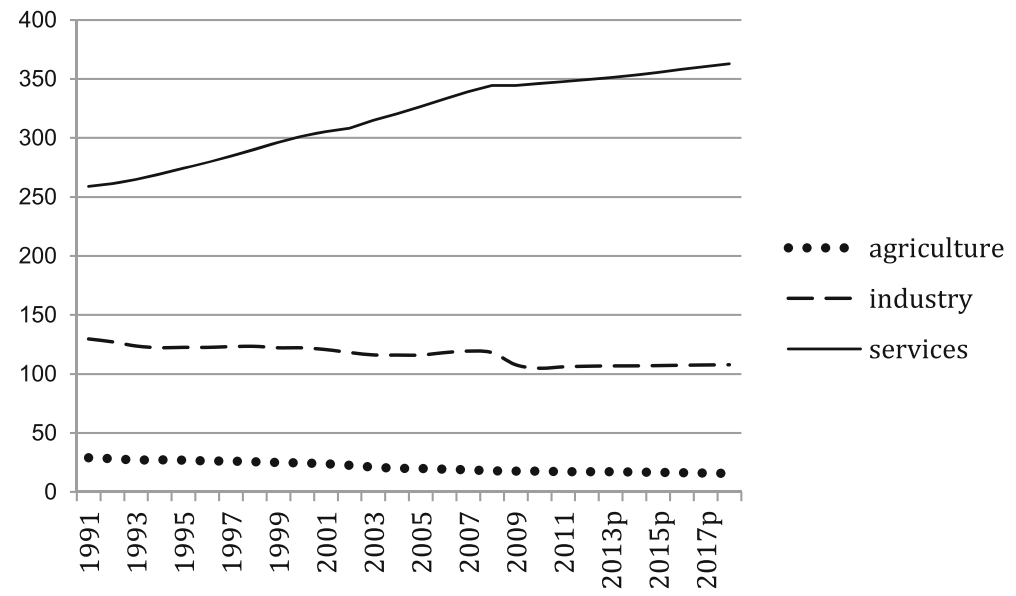

Fig. 2 Total employment by sector in developed economies and EU (millions). Source: International Labour Organisation-Trends Econometric Models, October 2013 


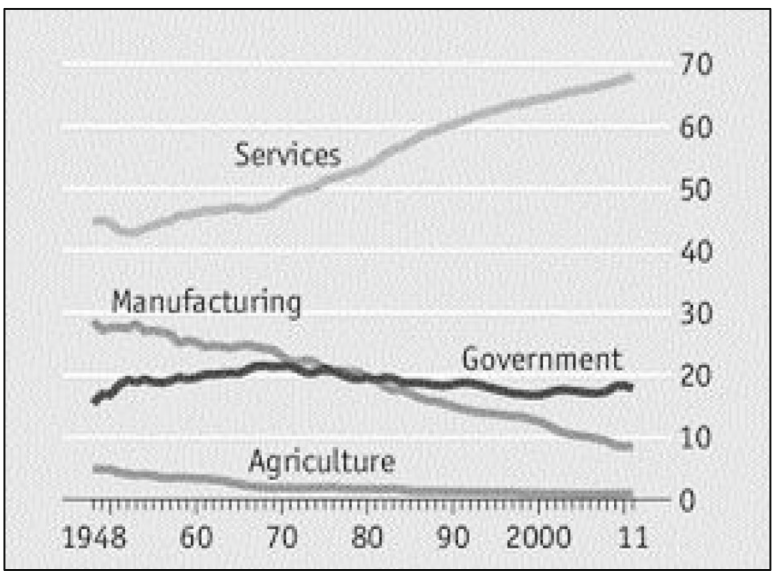

Fig. 3 US employment by sector, percentage of total employment. Source: US Bureau of Labour Statistics, picture (C) The Economist (18 January 2014)

third problem envisaged by Keynes as the really permanent one and as a direct consequence of technological unemployment. It is the most significant component of the human project. Let me call it the problem of 'leisure occupation':

Thus we have been expressly evolved by nature-with all our impulses and deepest instincts - for the purpose of solving the economic problem. If the economic problem is solved, mankind will be deprived of its traditional purpose. [...] Thus for the first time since his creation man will be faced with his real, his permanent problem - how to use his freedom from pressing economic cares, how to occupy the leisure, which science and compound interest will have won for him, to live wisely and agreeably and well [my emphasis].

Technological unemployment is what we have been planning all along, by relying on animals, other humans, science, technology, capital and compound interest. We have been trying to make ourselves redundant since time unmemorable so that we may be leisurely occupied. We have toiled hard in order not to toil anymore. But now that this historical opportunity is enjoyed by, or at least within reach for, a growing number of people during increasingly larger portions of their lives, we have been caught unprepared. Those of us who enjoy some free time are often awful investors of it. We waste it or kill it, seemingly oblivious of the titanic efforts and sacrifices made by past generations in order to place us in such fortunate circumstances. The old Adam does not know how to cope with his regained corner of paradise:

It is a fearful problem for the ordinary person, with no special talents, to occupy himself, especially if he no longer has roots in the soil or in custom or in the beloved conventions of a traditional society. To judge from the behaviour and the achievements of the wealthy classes to-day in any quarter of the world, the outlook is very depressing! For these are, so to speak, our advance guard-those who are spying out the promised land for the rest of us and pitching their camp there. For they have most of them failed disastrously, so it seems to me-those 
who have an independent income but no associations or duties or ties - to solve the problem [of leisure occupation, my addition] which has been set them. I feel sure that with a little more experience we shall use the new-found bounty of nature quite differently from the way in which the rich use it to-day, and will map out for ourselves a plan of life quite otherwise than theirs. For many ages to come the old Adam will be so strong in us that everybody will need to do some work if he is to be contented. We shall do more things for ourselves than is usual with the rich to-day, only too glad to have small duties and tasks and routines. But beyond this, we shall endeavour to spread the bread thin on the butter - to make what work there is still to be done to be as widely shared as possible. Three-hour shifts or a 15-hour week may put off the problem for a great while. For $3 \mathrm{~h}$ a day is quite enough to satisfy the old Adam in most of us!

In the leisure society, the risk is that there will be countless people bored and demotivated, undecided about what to do with their free time, their days at school, their weekends, their vacations, their bank holidays and their retirement. We may turn into 'idle creatures' - as Flavius describes them in Shakespeare's Julius Caesar-who 'being mechanical, [...] ought not walk upon a labouring day'. ${ }^{2}$ The mildly optimistic reply is that some of us will learn to live a life of leisure worth living (education is the key here), and those of us who will not will still be left with the opportunity of making the most of their leisure if they wish. Civilisation also means the freedom of being a couch potato. Unfortunately, two more problems will become increasingly pressing. Keynes does not discuss them in his essay, but they are clearly visible in our times.

In the long run, next century or next millennium, technological unemployment will turn into leisure occupation only if we will succeed in decoupling unemployment from the lack of income, the consequent social unrest and the related erosion of personal dignity, insofar as having a paid job is still seen in our present culture as synonymous with having a role in society. Call this the 'resource problem'. In other contexts, Keynes thought that solving the 'resource problem' was possible and worth striving for. I agree unreservedly. A society in which a minimal degree of financial independence and social welfare is guaranteed to all citizens will finally shift the existential problem of purpose from disoccupation (unemployment) to inoccupation. But for this to occur, the problem of inequality will have to be solved. ${ }^{3}$ For as long as our society is organised in such a way as to promote and privilege rare 'local maxima', that is, few, immense accumulations of wealth, the leisure society will remain a utopia. A cynic may then see the growth in inequality as a way of saving the masses from having to deal with the truly permanent problem of existential purpose. In rhetorical and colourful terms: 'make those idle creatures starve and they will not wonder about the meaning of life'. It is a silly idea that nobody should entertain, given its inconsistency with social fairness, equality and cohesion. The solution is a better design of the mechanisms that facilitate the distribution and circulation of wealth. In other words, the possibility of a leisure

\footnotetext{
${ }^{2}$ Shakespeare, Julius Caesar, Act 1 , Scene 1, 1-4.

${ }^{3}$ For a short and very accessible criticism of inequality in the USA, the reader may wish to consult Vanity Fair (Stiglitz 2011), an article published by a Nobel prize winner in economics Joseph Stiglitz. The article is discussed slightly more technically in The Economist 11 April (2011), negatively, and in The Economist 15 April (2011), positively. I agree with the latter.
} 
society is based on a redesign of the taxing system that minimises local maxima, as current debates on inequality and tax reform in the USA testify.

There is then the 'political problem'. As idle creatures, we may transform a potential 'liberal and leisure society' into an actual 'illiberal lazy society', in which the Biblical 'painful toil' is replaced by shallow entertainment as the ultimate source of existential distraction. It may seem a merely philosophical point, or even a problem worth having. But underestimating the risk of political distraction means being less able to explain (and hence find an answer to) why a society's economic growth may not be followed by any liberal and democratic improvement. 'Bread and games' (panem et circenses) has been a successful strategy of political appeasement and diversion whenever power has had the means to afford it. Today, this translates into a specific threshold in the growth of national GDP above which unemployment is not a problem, standard of living increases, hopes for a better life for oneself or at least one's children are kept alive if not fulfilled and social unrest is avoided so democratic, liberal demands are postponed and various forms of illiberalism can be ignored or tolerated. We know that in China, this figure is around $7 \%$ annual growth.

Solving the economic problem through technological unemployment, sustainable growth and fair redistribution of wealth, in order to arrive at a liberal, democratic, leisure society, in which education helps people to use their time (stay in the educational system), make the most of it (highly qualified skills for the increasingly specialised jobs) and enjoy it (abilities to find occupations and appreciate one's leisure): this is the blueprint not for utopia but for the human project we have been pursuing for a long time and that is worth all of our efforts. ${ }^{4}$

Authoritarians, fundamentalists, extremists and radicals of all political and religious kind could not disagree more. This is a serious challenge, but not the challenge with which I would like to close this article, which is represented by an internal criticism that shares the same liberal and democratic roots endorsed by the human project and even some aspects of Keynes' analysis.

On March 13, 2014, speaking in Washington, DC at The American Enterprise Institute - a private, conservative and not-for-profit institution for public policy research-Bill Gates identified the same problem analysed in 1930 by Keynes ${ }^{5}$ :

MR. GATES: [...] Software substitution, you know, whether its for drivers or waiters or nurses or even, you know, whatever it is you do. [...] Its progressing. And that's going to force us to rethink how these tax structures work in order to maximize employment, you know, given that, you know, capitalism in general, over time, will create more inequality and technology, over time, will reduce demand for jobs particularly at the lower end of the skill set. And so, you know, we have to adjust, and these things are coming fast. Twenty years from now, labor demand for lots of skill sets will be substantially lower, and I don't think people have that in their mental model.

\footnotetext{
${ }^{4}$ The idea is consistent with what has been argued in economics by Brynjolfsson and McAfee (2014). For a philosophical approach, see Floridi (2014).

${ }^{5}$ The transcript can be found in Gates (2014); the video with the whole interview is available online.
} 
Recall that almost $90 \%$ of the jobs in the US economy are in the service sector. Smart Information and Communications Technologies could easily create huge waves of unemployment. A killer app would refer to the number of jobs it would eliminate. So Gates is correct, although to anyone who read Keynes' essay, this is very old news. Both agree on identifying technological unemployment as a problem. But Gate's interpretation differs, so does his solution, and neither is convincing.

Gates treats technological unemployment as something that needs to be avoided at all costs. It is a philosophy that sees painful toil and not leisure occupation as humanity's destiny. Keynes had already replied to this view two generations ago:

I believe that this is a wildly mistaken interpretation of what is happening to us. We are suffering, not from the rheumatics of old age, but from the growing-pains of over-rapid changes, from the painfulness of readjustment between one economic period and another. The increase of technical efficiency has been taking place faster than we can deal with the problem of labour absorption.

If you have the wrong human project in mind, you end up misinterpreting technological unemployment as a curse, when in fact the curse is rather that of having to eat your food 'by the sweat of your brow'. And once technological unemployment becomes the problem, then the solution becomes that of preventing it or mitigating its consequences at all costs. So, coherently, Gates argues against raising the minimum wage and in favour of a shift from a progressive income tax to a progressive consumption tax:

MR. GATES: [...] I do think tax structures will have to move away from taxing payroll because society has a desire to have employment. Of all the inputs, you know, wood, coal plastic, cement, there's one that plays a special purpose, which is labor. And the fact that we've been able to tax labor as opposed to capital or consumption, you know, just shows that demand for labor was good relative to other things. Well, technology in general will make capital more attractive than labor over time. [...]

MR. BROOKS: So aligning the incentives in our economy to move away from taxing labor, moving to something like a progressive consumption tax is just a smart thing to do to stimulate - to have an economy that's better aligned?

MR. GATES: Well, I think economists would have said that a progressive consumption tax is a better construct, you know, at any point in history. What I'm saying is that it's even more important as we go forward because it - the distortion - I want to distort in the favor of labor. And so not only will we not tax labor, things like the earned income tax credit, you know, when people say we should raise the minimum wage, I think, boy, you know, I know some economists disagree. But I think, boy, I worry about what that does to job creation. The idea that through the income tax credit you would end up with a certain minimum wage that you'd receive, that I understand better than potentially damping demand in the part of the labor spectrum that I'm most worried about. [...] And the idea that consumption should be progressively taxed, I think that makes a 
lot of sense. People have tried to do that by doing particular taxes on luxury goods, some things like that. That's very - not very effective. It's sort of picking favourites type things. But yes, consumption should be progressively taxed. And we should understand the consumption. Inequality of consumption is more an injustice than a number in a book is.

MR. BROOKS: So inequality of consumption is the real inequality we should be worried about. I suppose you'd also say that inequality of opportunity is that which is the greatest affront to dignity. I think I'm sort of paraphrasing.

MR. GATES: Yeah, no, I agree with that.

It makes sense to tax consumption progressively. Indeed, experts agree that, if properly designed, consumption taxes encourage savings and can contribute to economic growth. I would add that they may also shape consumption patterns that are more environmentally friendly. For all these reasons, indirect consumption taxes, such as sales taxes or value added taxes, are very common in Europe and seem likely to increase. And they should be significantly progressive. But it seems strange to offer taxing consumption as an alternative to taxing income when a fine balance between the two is needed to take care not only of economic growth but also of a fairer welfare system and a much better redistribution of wealth. It is possible to reduce income inequality while boosting economic growth. ${ }^{6}$ And both are necessary in order to move a step closer to the leisure society and the fulfilment of the human project. Keeping minimum wages so low that it may be preferable to hire human workers rather than robots, and taxing people only for what they consume rather than for what they earn and own, would damage technological innovation and fail to improve the human condition.

\section{References}

Brynjolfsson, E., \& McAfee, A. (2014). The second machine age: work, progress, and prosperity in a time of brilliant technologies. New York: W. W. Norton \& Company.

Floridi, L. (2014). The fourth revolution-how the infosphere is reshaping human reality. Oxford: Oxford University Press.

Gates, B. (2014). From poverty to prosperity: a conversation with Bill Gates, American Enterprise Institute: transcript provided by DC Transcription, available online.

Keynes, J. M. (1930). Economic possibilities for our grandchildren: published in Keynes (1972), also freely available online.

Keynes, J. M. (1972). Collected writings vol. 9: essays in persuasion (2nd ed.). London: Macmillan.

OECD Economic Policy. (2012). Going for growth 2012. Reducing income inequality while boosting.

Stiglitz, J. (2011). Of the $1 \%$, by the $1 \%$, for the $1 \%$. Vanity fair 11 , available online.

The Economist. (11 April 2011). Inequality and politics-Stiglitz and the progressive Ouroboros.

The Economist. (15 April 2011). Inequality-the $1 \%$ solution.

The Economist. (18 January 2014). The future of jobs - the onrushing wave.

\footnotetext{
$\overline{{ }^{6} \text { (OECD Economic Policy 2012) }}$, Chapter 5, entitled "Reducing income inequality while boosting economic growth: Can it be done?" The answer is a qualified yes.
} 